\title{
Prevalence of Childhood Asthma in Preschool Children in Qalyubiya Governorate \\ http://bjas.journals.ekb.eg
}

A.A.Sobieh , A.S.Shahin and M.S.Ali

\author{
Pediatrics Dept., Faculty of Medicine, Benha Univ., Benha, Egypt
}

E-Mail:Mai@gmail.com

\begin{abstract}
Asthma is a genuine worldwide medical issue. Individuals of any age in nations all through the world are influenced by this constant aviation route issue that when uncontrolled can put extreme cutoff points on day by day life and is now and then lethal, it is more common in youngsters than in grown-ups. It was accounted for that the predominance of asthma is increasing. The point of the examination was to decide the commonness pace of bronchial asthma in a preliminary to recognize the extent of the issue of asthma and to distinguish some of hazard factors expanding the pervasiveness of it among preschool kids from 2-6years old in Qalubyia Governorate utilizing the ISAAC survey, 1000 understudies were remembered for this investigation (475 were guys and 525were females). in the period from Novaber 2019 to April 2020.The consequences of this poll among examined youngsters (1000 kid) indicated that: $164(16.4 \%)$ of considered understudies were asthmatics. Our investigation as respects sexual orientation and its connection to youth asthma demonstrated that, the predominance of asthma in male kids was $17.5 \%$ and in female youngsters was $15.4 \%$ and this distinction was measurably insignificant(P<0.05). days was increasingly regular in a time of 1-3 days. Determination: There was a high pervasiveness of asthma among kids. Asthma was found to influence rest of kids in a few viewpoints. The instructive degree of guardians had no impact on the predominance of asthma.
\end{abstract}

Keywords: Asthma, Asthma prevalence, Children asthma.

\section{Introduction}

Asthma is a typical and possibly genuine constant illness that forces a significant weight on patients, their families and the network. It causes respiratory side effects, restriction of movement, and flare-ups (assaults) that occasionally require critical social insurance and might be fatal [1].

The point of the examination was to decide the pervasiveness pace of bronchial asthma in a preliminary to distinguish the greatness of the issue of asthma and to recognize some of hazard factors expanding the commonness of it among preschool youngsters from 26years old in Qalubyia Governorate utilizing the ISAAC poll, 1000 understudies were remembered for this investigation (475 were guys and 525were females [2].

Universally, asthma is positioned sixteenth among the main sources of years lived with incapacity and 28th among the main sources of weight of ailment, as estimated by handicap balanced life years [3].

Barely any investigations have been led in Egypt to quantify asthma pervasiveness in kids, however dependent on accessible information, the predominance ranges from 3.25 to $9.4 \%$ [4]. Some particular reasons have been proposed as a reason for the expanded asthma pervasiveness, including both ecological and hereditary factors, for example, toxins, way of life, financial status, topographical territory, tobacco smoke allergens, viral diseases, low birth weight, and diet [5], the more noticeable of the referenced elements is the natural factor [6].

Asthma is a typical reason for crisis visits to clinics and nonappearance from school for school-matured kids; additionally, it causes dreariness which may even prompt demise [2]. Unfavorably susceptible issues including asthma cause high social and budgetary weight on the family and society [7].

The outcomes incorporate loss of work, nonappearance from school, hospitalizations, and low personal satisfaction [8].
Asthma is a non-reparable incessant issue, in any case, it has lower death rate than other comparative ceaseless issues [5]. History and understanding of asthma indications are considered as significant models in asthma determination, it additionally relies upon the reversibility and changeability of pneumonic capacity tests, wheeze inside a year is viewed as a marker for the conclusion of asthma [9. One of the traps in the asthma the board is under-determination of asthma in youngsters [10].

There were studies to decide asthma predominance performed relying upon a normalized global stock called the International Study of Asthma and Allergies in Children $[11$; in view of these past examinations, there was orderly audits that indicated the mean commonness of asthma in Iran somewhere in the range of 1998 and 2003 was $13 \%$ [12].

Asthma predominance in youngsters matured from 2 to 6 years in certain nations including Austria, Belgium, Finland, France, Italy, and Switzerland was accounted for to be under $10 \%$, while it was higher in different nations including Czech Republic (14.7\%), Norway (13.6\%), Bulgaria [13].

$(14.5 \%)$, and Ireland $(17.4 \%)$. The predominance of asthma was $17 \%$ in Kuwait . In Egypt, it was accounted for that asthma commonness was $4.8 \%$ in Egyptian newborn children and kids matured under 4 years, from five governorates [14], while predominance in kids was $7.7 \%$ in the Nile Delta area of Egypt.

These distinctions in asthma pervasiveness between nations might be credited to the distinction in atmosphere, air contamination, financial status, way of life, introduction to respiratory disease, and fluctuation of allergen levels [15]. The current examination was set up to assess the predominance of asthma in kids.

\section{Subjects and methods}

The aim of the study was to determine the prevalence rate of bronchial asthma in a trial to identify the magnitude of the problem of asthma and to identify some of risk 
factors increasing the prevalence of it among preschool children from 2-6years old in Qalubyia Governorate using the ISAAC questionnaire, 1000 students were included in this study (475 were males and 525were females).

All students were given a written questionnaire including personal data (name, age, sex, residence), history as regards asthma, complementary questions for risk factors, were taken into consideration as (history of breast feeding, father education, environmental conditions and exposure to tobacco smoke).

The questionnaire was distributed to the KGs children to be completed by their parents at home .

\section{Results}

The aftereffects of this survey among examined kids (1000 youngster) demonstrated that: 164 (16.4\%) of contemplated understudies were asthmatics.

Our examination as respects sexual orientation and its connection to youth asthma demonstrated that, the commonness of asthma in male kids was $17.5 \%$ and in female youngsters was $15.4 \%$ and this distinction was measurably insignificant $(\mathrm{P}<0.05)$.

Likewise the investigation found a higher level of quality of bronchial asthma among kids living in urban territories $(18.2 \%)$ contrasted with youngsters living in rustic regions $(14.6 \%)$.

As indicated by the seriousness of asthma it has been discovered that the asthmatic understudies were characterized into: Mild discontinuous $87(53.05 \%)$ of the complete asthmatic understudies, gentle industrious 59 $(35.97 \%)$ of the all out asthmatic understudies, moderate tenacious $11(6.71 \%)$ of the absolute asthmatic understudies, extreme tireless $7(4.27 \%)$ of the all out asthmatic understudies.

Asthma intensifications happened in winter season $(68.9 \%)$, and $(48.2 \%)$ of these intensifications prompted by upper respiratory tract diseases.

It was discovered that there is a higher factual increment of family ancestry of atopy among understudies with bronchial asthma (37.97\%).and a higher level of asthmatic understudies were presented to natural tobacco smoke $(21.7 \%)$.

The investigation discovered additionally a higher measurable critical increment of presentation to close by air contamination and creatures among asthmatic understudies $(37.5 \%)$.

There was a higher measurable noteworthy increment of medical clinic affirmation among understudies with serious and moderate asthma than understudies with gentle asthma.

The investigation found that about (79.9\%) of asthmatic understudies didn't take ordinary treatment (controller treatment), which might be because of damaged social insurance and healtheducation.

Our examination speak to that activity initiated asthma (EIA) happens in up to $59.1 \%$ of asthmatic understudies. What's more, the examination found a higher level of previous history of counterfeit taking care of among cases with asthma $(32.9 \%)$ contrasted with understudies without asthma and the thing that matters is measurably profoundly critical.

The sociodemographic attributes of examined understudies indicated that there were a higher level of asthma patients among the center financial gathering $(18.9 \%)$ contrasted with different gatherings, yet the thing that matters was measurably not noteworthy.

Table (1) Answers of participants about six questions.

\begin{tabular}{lc}
\hline Questions & N (\%) \\
\hline Did your children were disturbed during sleep as a result of breathing \\
problems? & $134(86.5 \%)$ \\
Yes & $21(13.5 \%)$ \\
No & \\
Do the breathing problems of your children affect their daily and school & \\
activities? & $73(47.1 \%)$ \\
Yes & $82(52.9 \%)$ \\
No & $50(32.3 \%)$ \\
Do your children speak only one or two words between breathing? & $105(67.7 \%)$ \\
Yes & \\
No & $86(55.5 \%)$ \\
Do you need quick relief drugs to solve the breathing problems of your \\
children? & $69(44.5 \%)$ \\
Yes & \\
No & \\
Do your children need cortisone administration via mouth to treat breathing \\
problems which & $40(25.8 \%)$ \\
other drugs can't do? & $115(74.2 \%)$ \\
Yes & \\
No & \\
\hline Tabld your child diagnosed of having bronchial asthma? & \\
\hline
\end{tabular}




\begin{tabular}{lc}
\hline Yes & $56(36.1 \%)$ \\
No & $99(63.9 \%)$ \\
\hline
\end{tabular}

Table (2) Distribution of asthma among studied students.

\begin{tabular}{|c|c|c|c|}
\hline Variable & & $\mathrm{N}=1000$ & $\%$ \\
\hline Asthma & & & \\
\hline Yes & & 164 & 16.4 \\
\hline No & & 836 & 83.6 \\
\hline & $\Rightarrow$ & & \\
\hline & $\infty$ & & \\
\hline & $=$ & & \\
\hline & $=$ & & \\
\hline & $\infty$ & n....... & \\
\hline
\end{tabular}

Fig (1) Distribution of asthma among the study group.

prevalence of asthma among studied students was $16.4 \%$.

Table (3) Presence of Environmental Factors among the studied students.

\begin{tabular}{lcc}
\hline Environmental Factors & $\mathbf{N = 4 0 4}$ & \% \\
\hline Animals (cats, doges, farm animals) & 178 & 17.8 \\
Outdoor pollution & 130 & 13 \\
Both & 96 & 9.6 \\
\hline
\end{tabular}

Table (4) Distribution of severity of bronchial asthma, hospitalization due to asthma and Exercise induced asthma among asthmatic students.

\begin{tabular}{lcc}
\hline Variables & $\mathbf{N = 1 6 4}$ & $\mathbf{\%}$ \\
\hline Severity of bronchial asthma & 87 & 53.05 \\
Mild intermittent & 59 & 35.97 \\
Mild persistent & 11 & 6.71 \\
Moderate persistent & 7 & 4.27 \\
Severe persistent & & \\
History of hospitalization due to asthma & 35 & 21.3 \\
Yes & 129 & 78.7 \\
No & & \\
Exercise induced asthma & 97 & 59.1 \\
Yes & 67 & 40.9 \\
No & & \\
\hline
\end{tabular}

Severity of asthma is determined according to the symptoms and their frequencies (ISAAC, 1998).

Exercise induced asthma $(59.1 \%)$ is one of the major

\section{Comparative data}

Table (5) Comparison between prevalence of asthma in male and female children in age group 2-6 years.

\begin{tabular}{lcccc}
\hline Sex & \multicolumn{5}{c}{$\begin{array}{c}\text { Asthmatics } \\
\mathbf{N = 1 6 4}\end{array}$} \\
\hline Malesn=475 & Number & \% & Z & P value \\
Femalesn=525 & 83 & 17.5 & & \\
\hline
\end{tabular}

There was no significant statistical difference in the prevalence of asthma between male and female children in age group triggering factors of pediatric bronchial asthma exacerbation. 
2-6 years.

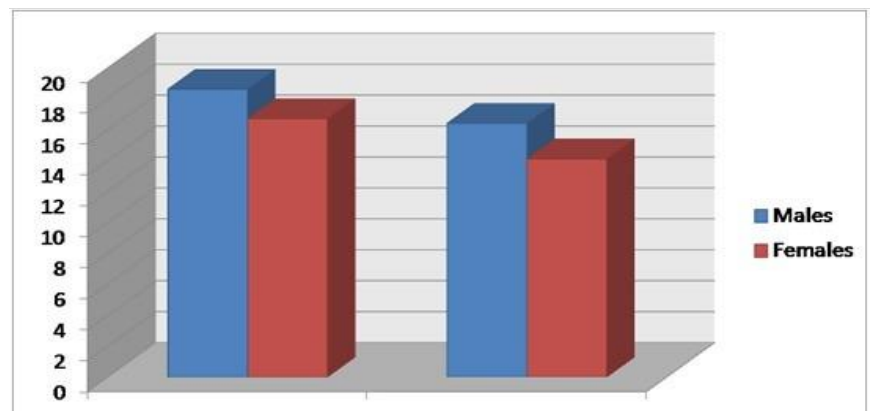

Fig (2) prevalence of asthma according to age and sex.

Table (6) Comparison between residence of students and prevalence of asthma.

\begin{tabular}{lccccc}
\hline Residence & \multicolumn{5}{c}{ Asthmatics } \\
\cline { 3 - 5 } & & N=164 \\
\hline Urban & $\mathbf{n = 5 0 0}$ & 91 & 18.2 & 1.54 & 0.12 (NS) \\
Rural & $\mathbf{n = 5 0 0}$ & 73 & 14.6 & & \\
\hline
\end{tabular}

There was no significant statistical difference between prevalence of asthma in urban and rural areas.

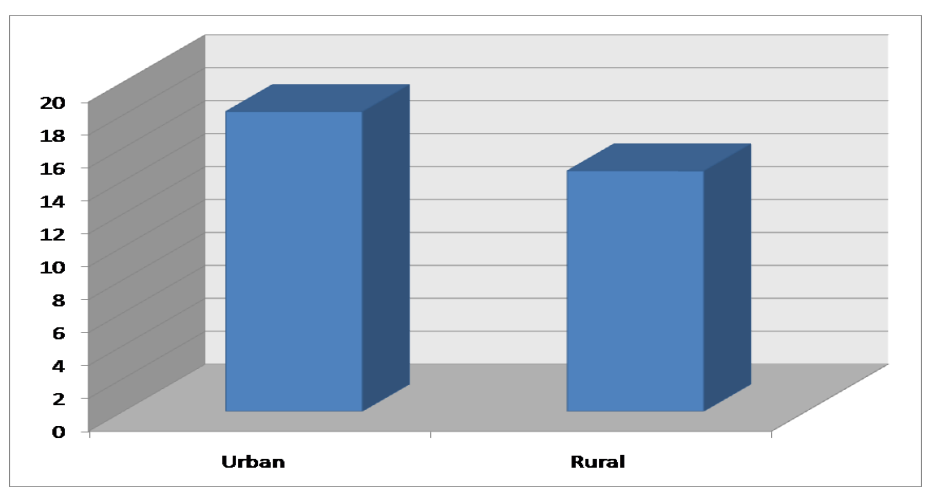

Fig (3) prevalence of asthma according to residence.

There was high significant statistical difference between asthmatic students as regards type of feeding in the first 6 months of life being more with artificial feeding than Exclusive breast feeding.

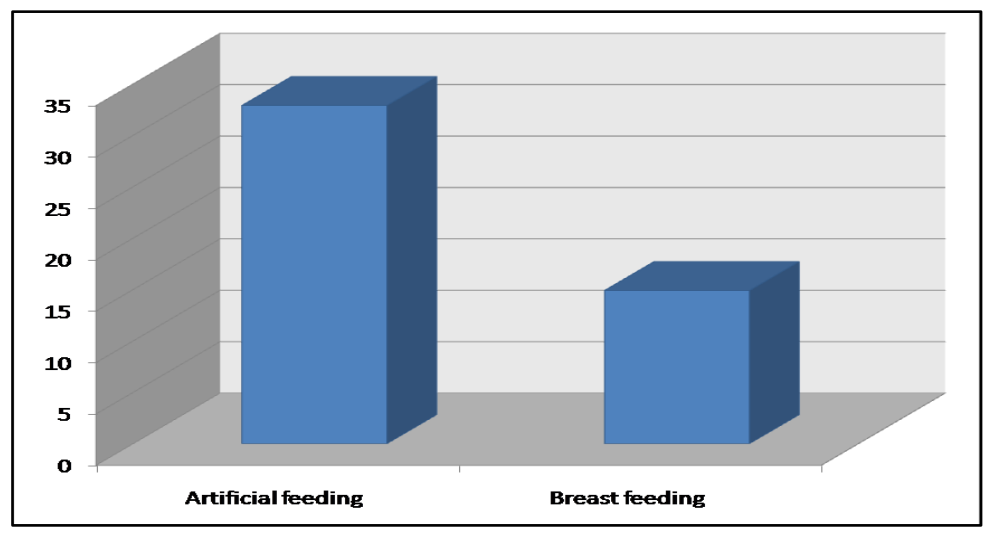

Fig (4) prevalence of asthma according to type of feeding. 
Table (7) Comparison between prevalence of asthma in children with history of passive smoking and those with no history of passive smoking.

\begin{tabular}{lccccc}
\hline Passive Smokers & \multicolumn{5}{c}{ Asthmatics $\mathbf{N = 1 6 4}$} \\
\cline { 3 - 6 } & & Number & \% & Z & P value \\
\hline Yes & $\mathbf{N = 4 1 0}$ & 89 & 21.7 & 3.78 & $<0.001$ (HS) \\
No & $\mathbf{N = 5 9 0}$ & 75 & 12.7 & & \\
\hline
\end{tabular}

There was high significant statistical difference passive smokers being more in the passive smokers. between prevalence of asthma in passive smokers and non

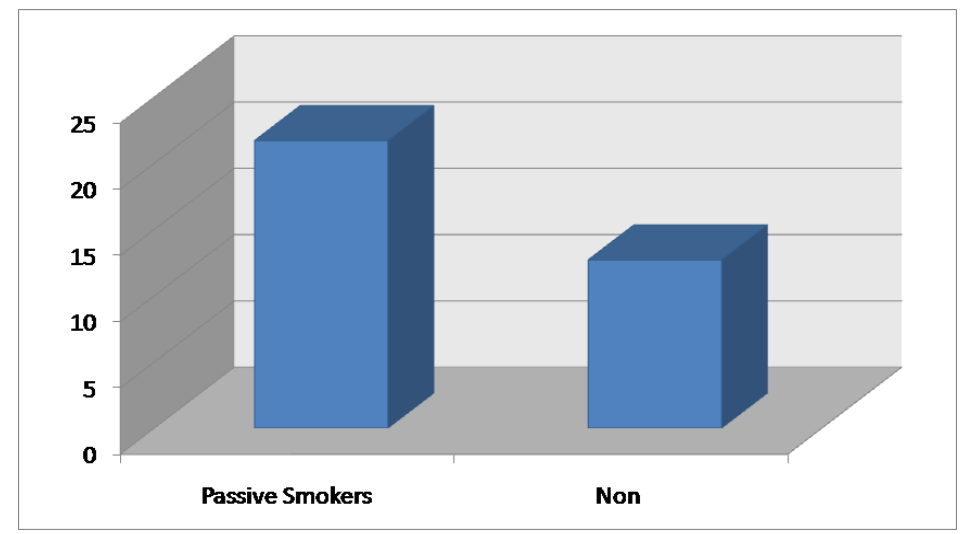

Fig (5) prevalence of asthma according to passive smoking.

Table (8) Distribution of asthma in relation to presence of nearby pollution.

\begin{tabular}{lcccc}
\hline Nearby pollution & \multicolumn{4}{c}{ Asthmatics $\mathbf{N = 1 6 4}$} \\
\cline { 2 - 5 } & Number & \% & $\mathbf{Z}$ & P value \\
\hline Outdoor pollution $\mathbf{n = 1 3 0}$ & 34 & 26.2 & 5.5 & $<0.001(\mathrm{HS})$ \\
Animal n=178 & 41 & 23.1 & 5.1 & $<0.001$ (HS) \\
Bothn=96 & 36 & 37.5 & 7.8 & $<0.001$ (HS) \\
Non=596 & 53 & 8.9 & Reference category \\
\hline
\end{tabular}

There was high significant statistical difference between prevalence of asthma in who exposed to nearby pollution than non exposed being more in the group exposed to both pollutions.

\section{Discussion}

Personal satisfaction can be adversely affected because of incessant lack of sleep influencing an individual's capacity to capacity to changing degrees at work or school. Asthma can influence an individual's efficiency because of continuous nonattendances from school or work [16].

It has been recorded that the commonness of pediatric asthma has risen forcefully in the course of recent years in numerous pieces of the world with huge topographical varieties [17].

The current work expected to decide the pervasiveness pace of bronchial asthma among preschool kids in Qalubyia Governorate ( KGs youngsters) in a preliminary to recognize the greatness of the issue of asthma and to distinguish some of hazard factors expanding the commonness of them.

This investigation was done in the period from November 2019 up to April 2020. An aggregate of 1000 understudies were enlisted from 4 urban areas (BanhaTouch - k.Shokr-Shubra El-Kheima) and 4 related towns (warwara - mansoura namol-asnite - Om biomy). The understudies were 475 guys and 525 females. Their ages were 2-6 years

A composed survey embraced from ISAAC poll in which various themes were added to accomplish our examination goals and converted into Arabic and appropriated to kids to be finished by the guardians of the understudies

In our examination, a few elements proposed to be unsafe for activating or disturbing the conditions were contemplated

Our outcomes indicated that commonness of bronchial asthma among (1000) preschool kids matured 2-6 years in Qalubyia Governorate was $16.4 \%$ of thestudied understudies.

In Egypt, various investigations attempted to gauge the predominance of asthma among kids . utilized interpreted and adjusted form of the ISAAC poll was disseminated to an example of 2645 younger students matured 6-8 years. They uncovered that wheeze during the most recent year was $14.7 \%$ and doctor analyzed asthma was $9.4 \%$. 
Furthermore, recommended a relationship between traffic thickness near spots of kids' home and predominance of respiratory ailments and all the more particularly of asthma or hypersensitive rhinitis side effects in them. Incessant introduction during early stages to traffic related poisons may quicken or even incite, among hereditarily delicate subjects, interruption of the ordinary administrative and fix forms in the end adding to the expansion of asthma frequency.

Our investigation found a higher level of asthmatic understudies among those living with creatures inside the house contrasted with those not having creatures in the house and the thing that matters was measurably profoundly critical. 23.1\% of understudies who had creatures inside the house were asthmatics and among the other gathering who didn't have creatures, the rate was 8.9 $\%(\mathrm{P}<0.001)$.

\section{Conclusion}

Pediatric asthma is considered the most common chronic pediatric chest problem, which has its impact on a child's quality of life.

The results of our questionnaire among studied students (1000 students) showed that: prevalence of bronchial asthma was $(16.4 \%)$ and 164 of studied students were asthmatics .

\section{References}

[1] M.J. Abramson, R.M. Puy, J.M. Weiner, Allergen immunotherapy for asthma (Cochrane Review). In: The Cochrane Library,Vol.25(5), PP. 213-2015,2013.

[2] D. Adeloye, K. Yee Chan, I. Rudan, H. Campbell, An estimate of asthma prevalence in Africa: a systematic analysis. Croat Med J ,Vol.54(6), PP.519-31,2017.

[3] E. Addo-Yobo , Exercise-induced bronchospasm in Ghana.Thorax , Vol. 52, PP. 161-265,2017.

[4] M. Ali A,Sallam, G. Fathy, Epidemiological study of the prevalence of bronchial asthma and other atopic diseases among school children in Egypt's of academicresearch, Vol.2(4), PP.215-216,2016.

[5] C. Aligne , M. Weitzman ,Risk factors for pediatric asthma. Contribution of poverty, race and urban residence. Am J respire Crit Care Mid,Vol. 162(3), PP.873-877,2013.

[6] M. Alkhalil, E. Schulman, J. Getsy, Obstructive Sleep Apnea Syndrome and Asthma: What Are the Links? Journal of Clinical Sleep Medicine : JCSM : Official Publication of the American Academy ofSleep Medicine, Vol.5(1),PP.71-78,2019.

[7] Allergic Rhinitis, its Impact on Asthma Special Issue: Allergic Rhinitis and its Impact on Asthma (ARIA) 2008 Vol. 63, IssueSupplement, Vol.86, PP. 8-160, 2008

[8] Allergic Rhinitis, its Impact ON Asthma Guidelines, Journal of Allergy and Clinical Immunology 2010 V. 9/8/2010.

[9] Al-Muhsen S, Johnson JR, Hamid Q (): Remodeling in asthma. J Allergy Clin Immunol, Vol.128, PP. 451-464, 2018

[10] O.A. Al-Rawas, B.M. Al Riyani, A.A. Al-Riami, A relatively high prevalence and severity of asthma, Allergic rhinitis and atopic eczema in school children in the Sultanate of Oman, Respirology , Mar, Vol. 8(1), PP.PP.69-76,2013

[11] American Lung Association (ALA), Measuring your peak flow rate. Retrieved from http://www.lung.org/lung-disease / asthma / taking -control-of-asthma/measuring-your-peak-flowrate.html, Vol.30(10), PP.312-325, 2016

[12] American Lung Association Dust Mites, 1-800LUNGUSA http://www.lung.org/ourinitiatives/healthy-air/ indoor / indoor -ai rpollutants/dust-mites. html ? referrer $=$ https :// www .google.com.eg/ Vol.50(25), PP.412-420, 2016

[13] S.D. Anderson How does exercise cause asthma attacks? Curr Opin Allergy Clin Immunol Vol. 6, PP.37-42, 2016

[14] B. Apelberg, Y. Aoki , J. Jakkola Systematic review: exposure to pets and risk of asthma and asthma-like symptoms. J. Allergy Clin. Immunol,Vol.107, PP. 455-460,2011

[15] ARIA Management of allergic rhinitis and its impact on asthma. Allergic Rhinitis and its Impact on Asthma Initiative. Rep,Vol. 1. PP.207-127,2001.

[16] S. Arslan, S. Ugurlu, Y. Demirel, G. Can Prevalence of asthma and allergic disease in Mid-Anatolia. Nobel Med,Vol. 8, PP. 30-34,2012.

[17] H. Awad Study of the prevalence of bronchial asthma and other atopic diseases among school children in Sharkia Governorate. Thesis submitted for partial fulfillment of master degree in pediatrics, under supervision Prof. Dr. Tharwat E. Deraz, Prof. of pediatrics. Faculty of Medicine, Ain Shams University, vol . 25 (5), PP.312-325, 2017

[18] Badea study of prevalence of asthma and other atopic diseases, Vol. 40(25), PP. 2011

[19] J. Kudzyte, E. Griska, J. Bojarskas , Time trends in the prevalence of asthma and allergy among 6-7-yearold children results from ISAAC phase I and III studies in Kaunas, Lithuania. Medicina (Kaunas), Vol.44(12), PP.944-52, 2008

[20] J. Ghaffari, M. Aarabi , The prevalence of pediatric asthma in the Islamic Republic of Iran: a systematic review and meta-analysis. J Pediatr Rev , Vol. 1(1), PP.2-11, 2013.

[21] M. Zedan , A. Settin , M. Farag , Prevalence of bronchial asthma among Egyptian school children. Egypt J Bronchol, Vol.3(2),PP.124-30, 2009.

[22] S.M. Ho , Environmental epigenetics of asthma: an update. J Allergy Clin Immunol , Vol. 126(3), PP.453-65,2010.

[23] F. Hamam, A. Eldalo, A . Albarraq, The prevalence of asthma and its related, Vol. 25(5),PP.320-335,2016. 